\title{
Effectiveness of suicide prevention programs for emergency and protective services employees: A systematic review and meta-analysis.
}

Katrina Witt (D.Phil) $)^{1, *}$; Allison Milner $(\mathrm{PhD})^{1,2}$; Amanda Allisey $(\mathrm{PhD})^{1,3}$; Lauren Davenport (M App Sc) ${ }^{1}$; Anthony D. LaMontagne $(\mathrm{ScD})^{1,2}$

${ }^{1}$ Centre for Population Health Research, School of Health and Social Development, Deakin University, Burwood, 3125, Victoria, Australia.

${ }^{2}$ Melbourne School of Population and Global Health, University of Melbourne, Melbourne, 3010, Victoria, Australia.

${ }^{3}$ Faculty of Business and Law, Deakin University, Burwood, 3125, Victoria, Australia.

RUNNING TITLE: Suicide prevention programs for emergency and protective services employees.

WORD COUNT: 4140.

* Corresponding author and institution at which the work was performed:

Dr. Katrina Witt

Centre for Population Health Research,

Deakin University,

221 Burwood Highway,

Burwood, VIC, 3125, Australia

Ph: +61392446758.

E: katrina.witt@deakin.edu.au

\section{Conflict of Interests Statement:}

The authors have no relevant interests to disclose

This is the author manuscript accepted for publication and has undergone full peer review but has not been through the copyediting, typesetting, pagination and proofreading process, which may lead to differences between this version and the Version of Record. Please cite this article as doi: 10.1002/ajim.22676 


\section{services employees: A systematic review and meta-analysis.}

Katrina Witt (D.Phil) $)^{1, *}$; Allison Milner $(\mathrm{PhD})^{1,2}$; Amanda Allisey $(\mathrm{PhD})^{1,3}$; Lauren Davenport (M App Sc) ${ }^{1}$; Anthony D. LaMontagne $(\mathrm{ScD})^{1,2}$

${ }^{1}$ Centre for Population Health Research, School of Health and Social Development, Deakin University, Burwood, 3125, Victoria, Australia.

${ }^{2}$ Melbourne School of Population and Global Health, University of Melbourne, Melbourne, 3010, Victoria, Australia.

${ }^{3}$ Faculty of Business and Law, Deakin University, Burwood, 3125, Victoria, Australia.

RUNNING TITLE: Suicide prevention programs for emergency and protective services employees.

WORD COUNT: 4140.

* Corresponding author and institution at which the work was performed:

Dr. Katrina Witt

Centre for Population Health Research,

Deakin University,

221 Burwood Highway,

Burwood, VIC, 3125, Australia

Ph: +61392446758.

E: katrina.witt@deakin.edu.au

Conflict of Interests Statement:

The authors have no relevant interests to disclose

\section{Abstract}

Background: This brief report summarizes the international literature on the effectiveness of suicide prevention programs for protective and emergency services employees.

Methods: A systematic search of 11 electronic databases was undertaken until 30 June, 2015. Quantitative meta-analysis was undertaken to investigate the effectiveness of these programs 
on suicide rates at post-intervention. Qualitative analyses were also used to identify program components that may be associated with reductions in suicide rates.

Results: A total of 13 studies were included. Only five reported sufficient information on suicide rates to enable inclusion in quantitative analyses, however. On average, these programs were associated with an approximate halving in suicide rates over an average follow-up period of 5.25 years ( $S D=4.2$; range: 1 -11) (Incident Risk Ratio $0.45,95 \%$ CI 0.31 - $0.65 ; 5$ studies; $I^{2} 14.8 \%$ ). Few programs integrated activities at the primary prevention level.

Conclusion: A greater focus on the relatively neglected area of workplace primary prevention could further improve suicide prevention effectiveness.

Keywords: Suicide prevention; emergency services; first responders; police. 


\section{BACKGROUND}

Although active employment is a protective factor against suicide, the majority of working age people who die by suicide are employed at the time of death [Yip and Caine, 2011; Milner et al., 2014]. Further, there is some evidence that working conditions may contribute to suicide risk in the employed adult population [Routley and Ozanne-Smith, 2012]. Job stress (i.e., high job demands coupled with low job control), for example, increases the risk of mental ill-health [Stansfeld and Candy, 2006], and suicide [Schneider et al., 2011]. Adverse chronobiological (e.g., frequent requirement for overtime work, shift work, night work) and/or physical working conditions (e.g., physically challenging or dangerous work) may also increase this risk [Baumert et al., 2014]. Occupational-based access to lethal means of suicide may also play a role in increasing suicide rates in certain occupational groups [Skegg et al., 2010].

Recent epidemiological work suggests that rates of suicide in protective and emergency services employees, including defense force, ambulance, and fire services employees are significantly higher than corresponding rates in members of the general working population [Milner et al., 2016; Milner et al., 2013]. One older review of suicide rates in police, additionally, find that although rates are elevated compared to comparable general population rates, suicide rates in regional police forces in particular are significantly higher than rates in the general population [Loo, 2003].

Heightened levels of job stress, particularly that stemming from routine occupational rather than operational sources, may play a role in increasing stress [Finney et al., 2013; Webster, 2013], mental ill-health [Garbarino et al., 2013], and suicidal behavior [Singh et al., 2013] in these occupations. Ready access to firearms and/or potent medications may also explain the increased risk of suicide in these occupations [Skegg et al., 2010]. 
The release of guidelines for workplace suicide prevention a decade ago [World Health Organization, 2006] has resulted in growing interest in the efficacy of workplace suicide prevention programs. There have been two recent reviews on workplace suicide prevention programs [Takada and Shim, 2010; Milner et al., 2015]; however these focused on a broad range of occupational groups, rather than protective and emergency services specifically. This is problematic given that emergency and protective services employees may have a number of additional workplace stressors as compared to other occupational groups [Johnson et al., 2005]. Therefore, we present a systematic review and meta-analysis of the characteristics and effectiveness of extant suicide prevention programs for protective and emergency services employees.

\section{MATERIALS AND METHODS}

The reporting of this review conforms to the Preferred Reporting Items for Systematic Reviews and Meta-analyses (PRISMA) statement [Liberati et al., 2009].

\subsection{Search Methodology}

We searched for literature indexed in eleven electronic databases that cover a wide range of disciplines, including: intervention research (CENTRL-Trials Register), policing (Australian Federal Police Digest [AFPD]; National Police Library [NPL]), criminology (Criminal Justice Abstracts [CJA]; National Criminal Justice Reference Service [NCJRS]), medical science (EMBASE; PubMED), public health (Global Health), psychology (PsycINFO), and social science (ProQuest Complete; SCOPUS). All databases were searched for eligible literature from their respective start dates until 30 June, 2015. 
We used a three tier search strategy to identify eligible studies. At the first stage, keywords inclusive of employees in the protective or emergency services (e.g., police OR "law enforcement" OR military OR army OR navy OR "air\$force" OR ambulance OR paramedic OR "fire\$fighter" OR "fire\$officer") were combined. At the second stage, these were combined with keywords inclusive of suicide (e.g., suicid* OR attempted suicid*). At the third stage, these were combined with keywords relating to prevention (e.g., prevent* OR control) as per the electronic search strategy for the EMBASE database as outlined in Supplementary Document SD1. Keywords were adapted for the specific requirements of each electronic database. No restrictions were placed on the grounds of date of publication, publication status, or language.

Reference lists of relevant reviews with a focus on suicide prevention in protective or emergency services employees were manually screened to identify further eligible studies [Bruce, 2010; Bagley et al., 2010; Conner and Simons, 2015; Miller, 2005; Zamorski, 2011; Harmon et al., 2016; Collins, 2008]. Experts in the field of suicide prevention were also contacted to assist with the identification of ongoing programs in this area. Corresponding authors were contacted to clarify aspects of the program, study design, participant recruitment, and other methodological details where necessary.

\subsection{Inclusion and Exclusion Criteria}

Studies were eligible for inclusion if: (1) the effectiveness of a universal/workforcewide suicide prevention program was evaluated; (2) the program was delivered to current or active employees in either the protective or emergency services (i.e., police, military, ambulance, correctional, and fire services); (3) either a randomized, pseudorandomized, or 
controlled before/after design was used; (4) numerical data on suicide rates were either reported or could be calculated from available data.

Given the focus of the review on universal suicide prevention programs, studies were excluded if: (1) participants were diagnosed with any psychiatric disorder and/or had been recruited from psychiatric treatment facilities; (2) participants were recruited on the basis of a history of previous suicide attempts or ideation. As the present review also focused on workplace suicide prevention activities, studies were also excluded if: (3) participants were veterans, retired, or otherwise not currently actively employed; (4) the program was not provided to all persons employed in workplaces; (5) the program adopted a postventative rather than preventative focus. Protocols and/or descriptions of programs that have not yet been implemented were also excluded. Although corresponding authors were contacted to request unpublished data, we also excluded studies if, after two attempts, we were unable to obtain raw data on either numbers of suicides and/or population size of the relevant focus during the study period. However, these studies were nevertheless included in the qualitative section of this review.

Studies were screened for eligibility using a two-stage process by two of KW, AA, or LP working independently. At the first stage, papers with relevant titles were selected for second screening. At the second stage, only those papers satisfying the inclusion criteria were retained following review of the full text. Disagreements were resolved via consensus discussions with a third researcher (AM).

\subsection{Data Extraction}

Methodological details and data were extracted using a standardized extraction form by two of either KW, AA, or LP working independently. Once again, disagreements were 
resolved via consensus discussions with AM. Methodological details included program name (if applicable), content, number of contact hours, facilitator expertise and experience, and intervention focus (i.e., primary, secondary and/or tertiary).

In line with public health and job stress prevention interventions frameworks [LaMontagne et al., 2014], workplace suicide prevention activities can be directed at primary, secondary, and/or tertiary levels. We understand primary prevention to include those activities which aim to prevent the occurrence of workplace suicides through, for example, efforts to minimize occupational sources of job stress, such as low decision latitude, psychological demands, effort-reward imbalance, and job insecurity [LaMontagne et al., 2007]. Secondary prevention activities encompass those designed to assist employees in how they respond to job stressors, for example through strategies to improve employees' ability to cope with or withstand occupational stressors, as well as assist in the identification of those at risk of suicide, for example through the provision of gatekeeper training for leaders/commanders. Finally, tertiary level activities encompass the provision of mechanisms for linking employees in with the prompt treatment when required, such as via crisis telephone hotlines, as well as support to those who have already engaged in suicide-related behaviors in returning to work [LaMontagne et al., 2014]. We also classified intervention activities as employee-directed (i.e., persons at risk of suicide) versus employer-directed (i.e., work-related sources of risk) in line with previous work [LaMontagne at al., 2007].

Data on the primary outcome, suicide mortality rates, were also extracted using one of two approaches. Where information on number of suicides, population size, and length of follow-up were reported for the treated and untreated cohort, these was entered directly. Where data on population size was missing, but information on suicide rates per 100,000 
persons and number of suicides were reported for each cohort, population size was estimated by dividing the number of suicides by the suicide rate, multiplied by 100,000 .

\subsection{Statistical Analysis}

Data on the primary outcome measure, suicide rates, were extracted by two of either KW, AA, or LP working independently.

Dichotomous measures of association, such as odds ratios (ORs), do not account for variability in follow-up duration [Tierney et al., 2007]. We therefore used the incidence rate ratio (IRR) and its accompanying 95\% confidence interval (CI) to synthesize results between studies included in the present review. The IRR has a similar interpretation to the OR and can take any value between zero and infinity with a value of one indicating no association [Sedgwick, 2010].

Between-study heterogeneity was estimated using the $I^{2}$ statistic which indicates the percentage of variability due to between-study factors (such as participant or methodological differences) rather than chance alone [Higgins et al., 2003]. Where $I^{2} \geq 75 \%$ we will undertake meta-regression analyses using the random effects model to explore potential causes as recommended [Higgins et al., 2003].

Risk of bias for the included studies was assessed using the GRADE criteria for randomized and cluster randomized controlled trials [Guyatt et al., 2011] or, for observational studies (e.g., pseudorandomized trials, controlled before/after designs), the GRACE criteria [Dreyer et al., 2014].

Analyses were undertaken in Comprehensive Meta-Analysis for Windows, version 3.3 [Biostat, 2014], using the random effects model. Forest plots were prepared for publication in Stata for Windows, version 13 [StatCorp, 2015]. For those programs that did 
not present quantitative data on the primary outcome measure, the first author $(\mathrm{KW})$ analyzed the content of these programs in NVivo for Windows, version 10 [QSR International, 2012]. This enabled analysis of the program components as described in the included studies to determine if they adopted a primary, secondary, and/or tertiary focus and the level of intervention (i.e., employee-directed vs. employer-directed). Additionally, qualitative comparative analysis was implemented to analyze similarities and differences in these dimensions between studies [Onwuegbuzie et al., 2012].

\subsection{Ethics Statement}

The data presented in this review were obtained from previously published reports available within the public domain. Specific institutional, ethics approval, and informed consent approval were therefore not required.

\section{RESULTS}

A total of 8,583 records were identified using the search strategy outlined in Supplementary Document SD1. Snowballing contributed an additional four records. This figure was reduced to 6,465 following deduplication. A total of 6,221 of these records were excluded at the first screening stage, whilst a further 232 were excluded following application of the inclusion and exclusion criteria at the second screening stage. Reasons for exclusion for all 232 records are given in Figure 1.

\section{INSERT FIGURE 1 HERE}

Two otherwise eligible studies [Litts et al., 2000; Staal, 2001] were excluded to avoid double-counting as the force, the intervention period, and the follow-up period overlapped substantially with a third [Knox et al., 2003]. A further study [Yosick, 2008] was similarly 
excluded as the force and prevention program overlapped with a more recent evaluation of the same program [Warner et al., 2011]. One study was excluded as the control group differed substantially from the intervention group in terms of risk of suicide at preintervention, thereby compromising exchangeability between cases and controls [McDaniel et al., 1990]. One further study was excluded as we were unable to obtain a copy of the fulltext following correspondence with both study authors and publishers [Steyn and Maphoso, 2005].

A total of seven studies were therefore included in qualitative analyses, whilst a further six were included in quantitative analyses. Further methodological details of these 13 studies are available in Table I.

\section{INSERT TABLE I HERE}

\subsection{Study Characteristics}

Most studies were of suicide prevention programs aimed at military personnel $[k=9$; Australian Defense Force, 2015; Dedić and Panic, 2007; James and Kowalski, 1996; Jones et al., 2001; Knox et al., 2003; Lapenaite and Vaicaitiene, 2008; Mehlum, 1998; Rozanov et al., 2002; Warner et al., 2011], followed by police personnel [ $k=3$; Mishara and Martin, 2012; Levenson Jr. et al., 2010; Welch, 1998], and fire-fighters [ $k=1$; Finney et al., 2015]. There were no eligible studies of suicide prevention programs for correctional or ambulance personnel.

The majority of these programs were implemented in the United States [USA; $k=6$; Finney et al., 2015; James and Kowalski, 1996; Jones et al., 2001; Knox et al., 2003; Levenson Jr. et al., 2010; Warner et al., 2011]. There was also one each from Australia 
[Australian Defense Force, 2015], Canada [Mishara and Martin, 2012], Lithuania [Lapenaite and Vaicaitiene, 2008], Norway [Mehlum, 1998], Serbia and Montenegro [Dedić and Panic, 2007], South Africa [Welch, 1998], and Ukraine [Rozanov et al., 2002].

\subsection{Program Components}

Only one program included primary prevention activities [Dedić and Panic, 2007]. However, the specific components constituting primary level prevention were not clearly specified. Two studies provided employee-directed primary prevention activities such as resiliency training [Warner et al., 2011; Welch, 1998]. However, only two studies included in this review addressed organizational sources of job stress by providing work-directed primary prevention activities such as leadership training for all supervisors [Knox et al., 2003; Mehlum, 1998].

Most programs instead focused on the provision of secondary level suicide prevention activities, including: awareness training [ $k=13$; Australian Defense Force, 2015; Dedić and Panic, 2007; Finney et al., 2015; James and Kowalski, 1996; Jones et al., 2001; Knox et al., 2003; Lapenaite and Vaicaitiene, 2008; Levenson Jr. et al., 2010; Mehlum, 1998; Mishara and Martin, 2012; Rozanov et al., 2002; Warner et al., 2011; Welch, 1998]. A number of programs $(k=9)$ also provided information on how to actively link persons experiencing a mental health crisis, including those who may be suicidal, with professional support services and were therefore classed as providing gatekeeper training [Australian Defense Force, 2015; Dedić and Panic, 2007; Finney et al., 2015; Knox et al., 2003; Mehlum, 1998; Mishara and Martin, 2012; Rozanov et al., 2002; Warner et al., 2011; Welch, 1998]. Other secondary prevention activities included: establishing dedicated mental health/suicide surveillance 
procedures [James and Kowalski, 1996; Knox et al., 2003; Lapenaite and Vaicaitiene, 2008; Warner et al., 2011], a crisis intervention team [Finney et al., 2015; James and Kowalski, 1996; Knox et al., 2003; Lapenaite and Vaicaitiene, 2008; Welch, 1998], implementing changes to personnel selection procedures [Dedić and Panic, 2007; Lapenaite and Vaicaitiene, 2008], or deployment pre-screening procedures [Warner et al., 2011], establishment of employee wellbeing programs [Finney et al., 2015; Mishara and Martin, 2012], alcohol and drug abuse treatment programs [James and Kowalski, 1996], and peer support programs [Knox et al., 2003; Levenson Jr. et al., 2010].

A number of programs also provided tertiary level prevention activities, including: a 24 hour crisis telephone hotline [Mehlum, 1998; Mishara and Martin, 2012; Welch, 1998], suicide intervention skills training [Australian Defense Force, 2015; Warner et al., 2011], annualized mental health 'check-ups' [Levenson Jr. et al., 2010], and the establishment of suicide postvention services [Warner et al., 2011; Welch, 1998].

\subsection{Quantitative Analyses}

For those programs that enabled calculation of the IRR and its accompanying $95 \%$ confidence interval at both pre- and post-intervention, overall implementation of these programs was associated with an approximate halving of the suicide rate at post-intervention (IRR $0.45,95 \%$ CI 0.31 to $0.65 ; 5$ studies; $I^{2}=14.8 \%$; $p<0.001$; Figure 2 ).

Subgroup analyses suggested that programs aimed at military (IRR 0.52, 95\% CI 0.44 to $0.62 ; 2$ studies; $p<0.001$; Figure 2 ) or police personnel (IRR $0.22,95 \%$ CI 0.31 to $0.65 ; 2$ studies; $p<0.001$; Figure 2) were associated with a significant reduction in suicide rates at post-intervention whilst, in a single program directed a fire-fighting personnel, there was no evidence of a significant reduction in suicide rates at post-intervention (IRR $0.82,95 \% \mathrm{CI}$ 
0.17 to 3.87 ; 1 study; $p=0.803$; Figure 2). Visual inspection of Figure 2, however, would suggest there is no evidence of a significant difference in effectiveness between these subgroups.

\section{INSERT FIGURE 2 HERE}

Two included studies reported information on suicide rates in an intervention cohort as compared to a control cohort, one in police personnel [Mishara and Martin, 2012], and a second in military personnel [Warner et al., 2011]. Overall, there was evidence of a significant treatment effect for these programs (IRR 0.33 , 95\% CI 0.16 to $0.70 ; 2$ studies; $I^{2}=9.5 \% ; p=0.003 ;$ Figure 3$)$.

Subgroup analyses would suggest that programs aimed at police personnel (IRR 0.22, 95\% CI 0.08 to $0.63,1$ study; $p=0.004$ ) but not military personnel (IRR $0.47,95 \%$ CI 0.18 to 1.21 ; 1 study; $p=0.119$ ) may be associated with significant reductions in suicide rates in the intervention cohort as compared to rates in the control cohort. However, as before, visual inspection of Figure 3 would suggest no significant difference between these subgroups.

\section{INSERT FIGURE 3 HERE}

\subsection{Qualitative analyses}

Seven studies did not provide sufficient information on post-intervention suicide rates to enable calculation of the IRR and its accompanying $95 \% \mathrm{CI}$; six in military personnel [Australian Defense Force, 2015; James and Kowalski, 1996; Jones et al., 2001; Lapenaite 
and Vaicaitiene, 2008; Mehlum, 1998; Rozanov et al., 2002] and one in police personnel [Levenson Jr. et al., 2010].

Two programs integrated awareness and gatekeeper training to improve the identification of those at risk of suicide and ensure these persons can be linked in with professional mental health services. The first adopted a face-to-face training style [Rozanov et al., 2002]. Two years following the implementation of this program the authors conclude the program was associated with a significant reduction in suicide rates $(32.6$ per 100,000 persons over a 12 year period at pre-intervention versus 16.7 per 100,000 persons in the two years post-intervention); although it should be noted that the pre-intervention rate is also reported as 37.8 per 100,000 persons in this report. However, as the denominator for this study is unclear, data could not be analyzed quantitatively. The second program used videos to deliver intervention materials [Jones et al., 2001]. The authors report that "...the introduction of annual suicide prevention...coincided with a drop in [the] Navy suicide rate...to $9.2 / 100 \mathrm{~K}$ ” for the period July, 2000 to June, 2001" [Jones et al., 2001; p.35]. However, although the authors report that "[ $\mathrm{t}]$ his is the lowest rate in 10 years..." [Jones et al., 2001; p.35], it is unclear whether this reduction is statistically significant. The effectiveness of a third program that combined awareness and gatekeeper training has not been evaluated to date [Australian Defense Force, 2015].

Given that the success of awareness and gatekeeper training may be dependent on the availability of effective tertiary-level programs for the treatment of those at imminent risk of suicide [Issac et al., 2009], two programs combined awareness and gatekeeper training with the establishment of crisis intervention services [James and Kowalski, 1996; Lapenaite and Vaicaitiene, 2008]. Although, in the former, “...the suicide rate...decreased to three in the 
past [two] years" [James and Kowalski, 1996; p.101], it is unclear whether this represents a significant reduction. The effectiveness of the latter program has not been assessed.

Resiliency has recently been identified as an important protective factor against suicide both within the general population [Johnson et al., 2011], and within the military specifically [Youssef et al., 2013]. One program provided stress resiliency training for all personnel in addition to awareness and gatekeeper training [Levenson Jr. et al., 2010]. This program, additionally, provided all personnel with a peer mentor and encouraged employees to attend an annualized 'check-up' with a mental health clinician. The goal of these sessions is to identify personal strengths and weaknesses, and to work on a program of improving these throughout the coming year. Despite being widely implemented in both the USA and Canada, this program has not been evaluated for effectiveness to date.

Only one program, aimed at members of the Norwegian Armed Forces, combined individually-focused awareness training, gatekeeper training, and crisis intervention with organizational-level interventions to address sources of organizational job stress [Mehlum, 1998; Mehlum and Reider, 2000]. Recognizing that leadership style can influence employee mental health [Skakon et al., 2010] and resilience [Bartone, 2006], and may even help to counteract the association between job stress and mental ill-health in these occupations [Russell, 2014], leadership training formed a cornerstone of this intervention. Although the authors report the program "has so far been very well received and implemented throughout the organisation" [Mehlum, 1998; p.1726], its efficacy on suicide rates at post-intervention remains unknown.

\section{DISCUSSION}

This systematic review and meta-analysis investigated the efficacy of 13 suicide prevention programs for protective and emergency services employees (e.g., police, military, 
ambulance, corrections, and fire services); six of which reported quantitative information on suicide mortality rates, and a further seven included in qualitative analyses only. This review therefore represents a comprehensive assessment of the effectiveness of these programs to date.

Of those programs reporting data to enable calculation of the post-intervention suicide mortality rate, there was evidence that these programs were associated with an approximate halving of the suicide mortality rate over an average follow-up period of 5.3 years $(S D=4.2$; range 1 to 11 years). Two further studies reported information on suicide mortality rates in a trained versus untrained cohort, one in the military and one in the police. However, there was no evidence for a significant effect of these programs on suicide rates over an average followup period of 6.1 years $(S D=6.9$, range 1.3 to 11 years $)$.

In line with previous work [Edlavitch and Bryns, 2015], most included studies focused on secondary and tertiary-level prevention activities. Additionally, only one of the included studies targeted organizational factors [Mehlum, 1998], despite past work suggesting that organizational, rather than operational, sources appear to be stronger predictors of stress [Finney et al., 2013; Webster, 2013] and suicidal behavior in these occupations. Given this, suicide prevention initiatives that address primary sources of stress, such as operational factors, as well as secondary and tertiary initiatives, may result in further reductions in suicide rates.

\subsection{Limitations}

Most of the suicide prevention programs included in this review were multicomponent. It is therefore difficult to identify which component, if any, may be associated with efficacy. For example, although there is interest in the role of resiliency 
training for stress management in these occupations [McCraty and Atkinson, 2012], there is presently little evidence of a preventive effect for resiliency training on suicidal behavior [Zamorski, 2011].

Additionally, given the rarity of suicide as an outcome measure, it is notable that no eligible program included more proximal outcomes, such as suicide attempts or ideation, which we have previously found to be associated with exposure to job stressors [Milner et al, 2016]. Further, no study evaluated the effectiveness of these programs on suicide prevention literacy. Future work in this sphere should consider reporting data on a greater range of relevant outcome measures to help with the identification of programs with the greatest promise in reducing suicide and other relevant adverse outcomes. However, given the limited number of eligible programs identified, and the relative lack of data on long-term outcomes following the implementation of these programs, there is currently a lack of firm evidence on which to ground occupational policy with respect to the prevention of suicide in these occupational groups currently.

Lastly, there have been so few empirical evaluations of suicide prevention programs aimed at protective and/or emergency services personnel: this review identified just 13 and half of these did not report sufficient information on suicide mortality rates to enable calculation of the IRR.

\subsection{Bias and Quality of the Included Studies}

A number of programs included in this review have also not been formally evaluated to date [Australian Defense Force, 2015; James and Kowalski, 1996; Jones et al., 2001; Levenson Jr. et al., 2010; Mehlum, 1998; Rozanov et al., 2002]. For one further study, data on effectiveness has not been published despite authors reporting that an evaluation was 
underway [Lapenaite and Vaicaitiene, 2008]. Publication bias therefore cannot be ruled out; particularly as we were unable to undertake tests for funnel plot asymmetry as fewer than 10 independent trials were included in the review. The development of, and adherence to, guidelines for the evaluation of suicide prevention programs is required to improve design and reporting of studies in this area [Davis et al., 2014; Sareen et al., 2014].

Study quality, measured according to the GRACE criteria [Dreyer et al., 2014], was in general poor with biases most commonly apparent for aspects of study design (e.g., Was the primary outcome measured or identified in an equivalent manner between the intervention and control group?; Were important covariates/confounders/effect modifiers recorded?) and methodology (e.g., If comparisons were used, were they concurrent comparators or, if not, did the authors justify the use of historical controls?; Were important confounding/effect modifying variables taken into account in the design/analysis?; Were any meaningful analyses conducted to test key assumptions on which primary results are based?).

\subsection{Conclusions}

Suicide prevention programs for protective and emergency services personnel warrant further evaluation. Clearer reporting of suicide mortality rates in both the target and comparison populations, as well as the background community rate, would also help to establish whether these programs are truly effective or, rather, whether the results reported for these programs to date might be explained wider macro-environmental level changes or other factors.

\section{Author Contributions:}


KW had the initial idea for the review, conducted the systematic review and all metaanalyses. AM, AA, and LD contributed to screening and drafting. All authors approved the final manuscript for publication.

\section{Acknowledgements:}

The authors wish to thank Lars Mehlum for providing copies of his publications, and William McDaniel for providing data clarification. The authors also wish to thank Lorraine Driscoll of Deakin University Library Service for obtaining copies of out-of-print publications, Lisa Schwoerer for assistance with translation of foreign language publications and, for assistance with mathematical data extraction and advice, Benjamin Davies.

\section{Funding Statement:}

No specific sources of funding were received for this project. However, the authors are supported by grants from a National Health and Medical Research Council (NHMRC) Partnership grant (APP1055333), including contributions from the Victorian Health Promotion Foundation (VicHealth), WorkSafe Victoria, and the Institute for Safety, Compensation \& Rehabilitation Research (ISCRR). The authors also report additional support from the Victorian Health Promotion Foundation Centre (\#15732) and an NHMRC Capacity Building Grant (\#546248).

\section{References}

Australian Defence Force. 2015. Australian Defence Force Suicide Prevention Program (ADF SPP). Accessed 25 July, 2015 from: http://www.defence.gov.au/ Health/DMH/SuicidePreventionProgram.asp 
Bagley S, Munjas B, Shekelle P. 2010. A systematic review of suicide prevention programs for military or veterans. Suic Life-Threat Behav, 40, 257-65.

Bartone P. 2006. Resilience under military operational stress: Can leaders influence hardiness? Mil Psychol, 18, s131-s48.

Baumert J, Schneider B, Lukaschek K, Emeny RT, Meisinger C, Erazo N, Dragano N, Ladwig KH. 2014. Adverse conditions at the workplace are associated with increased suicide risk. J Psychiatr Res, 57, 90-5.

Biostat Corporation. 2014. Comprehensive Meta-Analysis (Version 3.3.070). Englewood, NJ: Biostat Corporation.

Bruce M. 2010. Suicide risk and prevention in veteran populations. Ann New York Acad Sciences, 1208, 98-103.

Collins M. 2008. Correction Officer Stress and Suicide [MA (Social Policy Studies) Dissertation]. New York: State University of New York.

Conner K, Simons K. 2015. State of innovation in suicide intervention research with military populations. Suic Life-Threat Behav, 45, 281-92.

Davis-Molock S, Heekin JM, Matlin SG, Barksdale CL, Gray E, Booth CL. 2014. The baby or the bath water? Lessons learned from the National Action Alliance for Suicide Prevention Research Prioritization Task Force literature review. Am J Prevent Med, 47, s115-s21.

Dedić G, Panic M. 2007. Suicide prevention program in the army of Serbia and Montenegro. Mil Med, 172, 551-5.

Dreyer N, Velentgas P, Westrich K, Dubois R. (2014). The GRACE checklist for rating the quality of observational studies of comparative effectiveness: A tale of hope and caution. J Manag Care Pharm, 20, 301-08. 
Edlavitch S, Byrns P. 2015. Primary prevention research in suicide. Crisis, 35, 69-73.

Finney EJ, Buser SJ, Schwartz J, Archibald L, Swanson R. 2015. Suicide prevention in the fire service: The Houston Fire Department (HFD) model. Aggress Viol Behav, 21, 14.

Finney C, Stergiopoulos E, Hensel J, Bonato S, Dewa CS. 2013. Organizational stressors associated with job stress and burnout in correctional officers: A systematic review. BMC Pub Health, 13, 82.

Garbarino S, Cuomo G, Chiorri C, Magnavita N. 2013. Association of work-related stress with mental health problems in a special police force unit. BMJ Open, 3, e002791.

Guyatt G, Oxman A, Vist G, Kunz, R, Brozek J, Alonso-Coello P, Montori V, Akl EA, Djulbegovic B, Falck-Ytter Y, Norris SL, Williams JW Jr., Atkins D, Meerpohl J, Schünemann HJ. 2011. GRADE guidelines 4: Rating the quality of evidence - study limitations (risk of bias). J Clin Epidemiol, 64, 407-15.

Harmon L, Cooper RL, Nugent WR, Butcher JJ. 2016. A review of the effectiveness of military suicide prevention programs in reducing rates of military suicides. J Hum Behav Social Environ, 26, 15-24.

Higgins J, Thompson S, Deeks J, Altman DG. 2003. Measuring inconsistency in metaanalysis. BMJ, 327, 557-60.

Issac M, Elias B, Katz LY, Belik S-L, Deane FP, Enns MW, Sareen J. 2009. Gatekeeper training as a preventative intervention for suicide: A systematic review. Canadian $\mathbf{J}$ Psychiatry, 54, 260-8.

James L, Kowalski T. 1996. Suicide prevention in an Army infantry division: A multidisciplinary program. Mil Med, 161, 97-101. 
Johnson S, Cooper C, Cartwright S, Donald I, Taylor P, Millet C. 2005. The experience of work-related stress across occupations. J Manag Psychol, 20, 178-87.

Johnson J, Wood A, Gooding P, Taylor PJ, Tarrier N. 2011. Resilience to suicidality: The buffering hypothesis. Clin Psychol Rev, 31, 563-91.

Jones DE, Kennedy KR, Hourani L, Hawkes C, Long MA, Robbins D. 2001. Suicide prevention in the Navy and Marine Corps: Applying the public health model. Navy Med, 92, 31-6.

Knox KL, Litts DA, Talcott GW, Catalano Feig J, Caine ED. 2003. Risk of suicide and related adverse outcomes after exposure to a suicide prevention programme in the US Air Force: Cohort study. BMJ, 327, 1376.

Lapenaite D, Vaicaitiene R. 2008. Lowering suicide risk: Situation and prevention measures in the Lithuanian Armed Forces. In: Wiederhold B (ed). Lowering Suicide Risk in Returning Troops: Wounds of War. Amsterdam, Netherlands: IOS Press.

LaMontagne A, Keegel T, Vallance D. 2007. Protecting and promoting mental health in the workplace: Developing a systems approach to job stress. Health Promot J Aust, 18, $221-8$

LaMontagne A, Martin A, Page K, Reavley NJ, Noblet AJ, Milner AJ, Keegel T, Smith PM. (2014). Workplace mental health: Developing an integrated intervention approach. BMC Psychiatry, 14, 131.

Levenson R Jr., O'Hara A, Clark R Sr. 2010. The Badge of Life psychological survival for police officers program. Int J Emerg Ment Health, 12, 95-102.

Liberati A, Altman G, Tetzlaff J, Mulrow C, Gøtzsche PC, Ioannidis JPA, Clarke M, Devereaux PJ, Kleijnen J, Moher D. 2009. The PRISMA statement for reporting 
systematic reviews and meta-analyses of studies that evaluate healthcare interventions: Explanation and elaboration. BMJ, 339, b2700.

Litts D, Moe K, Roadman C, Janke R, Miller J. 2000. Suicide prevention among active duty Air Force personnel - United States, 1990-1999. J Am Med Assoc, 382,193-4.

Loo R. 2003. A meta-analysis of police suicide rates: Findings and issues. Suicide LifeThreat Behav, 33, 313-25.

McCraty R, Atkinson M. 2012. Resilience training program reduces physiological and psychological stress in police officers. Global Adv Health Med, 1, 44-66.

McDaniel W, Rock M, Grigg J. 1990. Suicide prevention at a United States Navy Training Command. Mil Med, 155, 173-5.

Mehlum L. 1998. Forebygging av selvmord blant unge - nyere erfaringer fra Forsvaret [Prevention of suicide in young people - recent experiences from the armed forces]. Tidsskr Nor Loegeforen, 118, 1724-6.

Mehlum L, Reider S. 2000. Suicide prevention in the military: Recent experiences from the Norwegian Armed Forces. Int Rev Armed Forces Med Serv, 74, 1724-26.

Miller L. 2005. Police officer suicide: Causes, prevention, and practical intervention strategies. Int J Emerg Ment Health, 7, 101-14.

Milner A, Morrell S, LaMontagne A. 2014. Economically inactive, unemployed and employed suicides in Australia by age and sex over a 10-year period: What was the impact of the 2007 economic recession? Int J Epidemiol, 43, 1500-7.

Milner A, Page K, Spencer-Thomas S, LaMontagne AD. 2015. Workplace suicide prevention: A systematic review of published and unpublished activities. Health Promot Int, 30, 29-37. 
Milner A, Spittal MJ, Pirkis J, LcMontagne AD. 2013. Suicide by occupation: Systematic review and meta-analysis. Br J Psychiatry, 203, 409-16.

Milner A, Witt K, Maheen H, LaMontagne AD. 2016. Suicide among emergency and protective service workers: A retrospective mortality study in Australia, 2001 to 2012. Work, accepted for publication 7 June, 2016.

Mishara B, Martin N. 2012. Effects of a comprehensive police suicide prevention program. Crisis, 33, 162-8.

Onwuegbuzie A, Leech N, Collins K. 2012. Qualitative analysis techniques for the review of literature. Qualitative Report, 17, 1-28.

QSR International. 2012. NVivo Qualitative Data Analysis Software (Version 10). Burlington, MA: QSR International.

Routley V, Ozanne-Smith J. 2012. Work-related suicide in Victoria, Australia: A broad perspective. Int J Injur Cont Safety Prevent, 19,131-4.

Rozanov V, Mokhovikov A, Stiliha R. 2002. Successful model of suicide prevention in the Ukraine military environment. Crisis, 23, 171-7.

Russell L. 2014. An empirical investigation of high-risk occupations: Leader influence on employee stress and burnout among police. Management Research Review, 37, 36784.

Sareen J, Isaak C, Katz LY, Bolton J, Enns MW, Stein MB. 2014. Promising strategies for advancement in knowledge of suicide risk factors and prevention. Am J Prevent Med, 47, s257-63.

Schneider B, Grebner K, Schnabel A, Hampel H, Georgi K, Seidler A. 2011. Impact of employment status and work-related factors on risk of completed suicide: A casecontrol psychological autopsy study. Psychiatry Res, 190, 265-70. 
Sedgwick P. 2010. The incidence rate ratio. BMJ, 341, c4804.

Singh R, Ram M, Sharma M. 2013. Predictors of suicidal ideation among police personnel. J Organis Hum Behav, 2, 45-52.

Skakon J, Nielsen K, Borg V, Guzman J. 2010. Are leaders' well-being, behaviours and style associated with the affective well-being of their employees? A systematic review of three decades of research. Work and Stress, 24, 107-39.

Skegg K, Firth H, Gray A, Cox B. 2010. Suicide by occupation: Does access to means increase the risk? Aust N Z H Psychiatry, 44, 429-34.

Staal M. 2001. The assessment and prevention of suicide for the 21st centuary: The Air Force's Community Awareness Training Model. Mil Med, 166, 195-8.

Stansfeld S, Candy B. 2006. Psychosocial work environment and mental health - a metaanalytic review. Scand J Work Environ Health, 32, 443-62.

StataCorp. 2015. Stata/SE for Windows (Version 13.1). College Station, TX: StataCorp.

Steyn R, Maphoso L. 2005. Micro or macro approach to suicide prevention? Preliminary results from a small sample. In: Madu N, Govender S (eds). Mental health and psychotherapy in Africa. Sovenga, South Africa: Press of the University of Limpopo, 511-31.

Takada M, Shima S. 2010. Characteristics and effects of suicide prevention programs: Comparison between workplace and other settings. Indust Health, 48, 416-26.

Tierney J, Stewart L, Ghersi D, Burdett S, Sydes MR. 2007. Practical methods for incoporating summary time-to-event data into meta-analysis. Trials, 8, 16.

Warner CH, Appenzeller GN, Parker JR, Warner C, Diebold CJ, Greiger T. 2011. Suicide prevention in a deployed military unit. Psychiatry, 74, 127-41. 
Webster J. 2013. Police officer perceptions of occupational stress: The state of the art. Policing, 36, 636-52.

Welch J. 1998. Life Savers: A suicide prevention programme helping South African Police Service (SAPS) to cope with post-apartheid era. People Management, 4, 46-8.

World Health Organization. 2006. Preventing Suicide A Rescource at Work. Geneva, Switzerland: World Health Organization.

Yip PS, Caine ED. 2011. Employment status and suicide: The complex relationships between changing unemployment rates and death rates. J Epidemiol Comm Health, 65, 733-6.

Yosick T. (2008). Prevention of suicides in the United States Army. In: Wiederhold B (ed). Proceedings of the NATIO Advanced Research Workshop on Wounds of War: Lowering Suicide Risk in Returning Troops. Brussles, Belgium: IOS Press, 98-101.

Youssef N, Green K, Beckham J, Elbogen EB. 2013. A 3-year longitudinal study examining the effect of resilience on suicidality in veterans. Ann Clin Psychiaty, 25, 59-66.

Zamorski M. 2011. Suicide prevention in military organizations. Int Rev Psychiatry, 23, 17380.

Figure Legends: 
Figure 1. PRISMA flow-chart documenting records identified following a systematic search of suicide prevention programs for emergency and protective services employees.

Figure 2. Random effects incident rate ratio (IRR) and its accompanying 95\% confidence interval $(\mathrm{CI})$ for suicide rates at post-intervention.

Figure 3. Random effects incident rate ratio (IRR) and its accompanying 95\% confidence interval (CI) for suicide rates in an intervention cohort as compared to a control cohort.

Table I: Methodological characteristics of suicide prevention programs for emergency or protective services employees included in this review.

\begin{tabular}{|c|c|c|c|c|c|c|c|}
\hline Author, Year & Country & Population & Coverage & $\begin{array}{c}\text { Effective } \\
N^{1}\end{array}$ & Design & $\begin{array}{c}\text { Date of } \\
\text { Implementation }\end{array}$ & $\begin{array}{c}\text { Follow-up } \\
\text { Period }\end{array}$ \\
\hline $\begin{array}{l}\text { Australian Defence } \\
\text { Force, } 2015\end{array}$ & Australia & $\begin{array}{c}\text { Military } \\
\text { (Armed Forces) }\end{array}$ & Nation & $\begin{array}{c}\text { Not } \\
\text { Stated }\end{array}$ & Pre/Post intervention & Unclear & N/A \\
\hline Dedić, 2007 & $\begin{array}{c}\text { Serbia \& } \\
\text { Montenegro }\end{array}$ & Military (Army) & Nation & 20,000 & Pre/Post intervention & December, 2003 & 2 years \\
\hline Finney, 2015 & USA & Fire Department & Department & 3,810 & Pre/Post intervention & January, 2007 & 7 years \\
\hline
\end{tabular}

- Awareness training (onl can also be delivered a duration by chaplains health professionals;

- Gatekeeper training (le delivered by defence $\mathrm{m}$ and/or trained psycholog

- Applied Suicide Inte (ASIST) (interactive duration) delivered by mental health profession

- Suicide Risk Assessm duration unclear) desi officers, psychologists, with training and expe risk assessment.

- Improved psychologica recruitment;

- Awareness training distributed to all perso unclear duration);

- Gatekeeper training (uno

- Awareness training (ser duration; distribution of

- Gatekeeper training (8 
James, 1996

USA

Military (Army)
USA

Jones, 2001

USA
Military
(Navy \& Marine Corps)

Knox, 2003
Division

Not
Stated

Pre/Post intervention

Staged between

late 1992 to

early 1994.

Nation

Not

Stated

407,782 2
Pre/Post intervention

Pre/Post Intervention
Mid 2000

Full implementtation achieved in early 1997
N/A

Crisis intervention team

- Awareness training (se duration delivered by science specialists", ha

- Crisis intervention team

- Centralized surveillance

- Alcohol and drug abuse

- Awareness training (u via video.

- Awareness training (u via chief of staff;

- Gatekeeper training (un

- Broadening of com personnel capacity;

- Peer support system

- Leadership training;

- Behavioral health risk

- Crisis intervention team

- Centralized surveillance

- Policy revisions to investigation are assess

- Privacy policy around to facilitate help-seeking

Table continued over ...

\begin{tabular}{|c|c|c|c|c|c|c|c|}
\hline Author, Year & Country & Population & Coverage & $\begin{array}{c}\text { Effective } \\
N^{1} \\
\end{array}$ & Design & $\begin{array}{c}\text { Date of } \\
\text { Implementation } \\
\end{array}$ & $\begin{array}{c}\text { Follow-up } \\
\text { Period } \\
\end{array}$ \\
\hline Lapenaite, 2008 & Lithuania & $\begin{array}{c}\text { Military } \\
\text { (Armed Forces) }\end{array}$ & Nation & $\begin{array}{l}\text { Not } \\
\text { Stated }\end{array}$ & Pre/Post intervention & Early 2005 & N/A \\
\hline Levenson Jr., 2010 & USA & Police & Nation & $\begin{array}{l}\text { Not } \\
\text { Stated }\end{array}$ & Pre/Post intervention & January $2008^{5}$ & N/A \\
\hline Mehlum, 1998 & Norway & $\begin{array}{c}\text { Military } \\
\text { (Armed Forces) }\end{array}$ & Nation & 33,000 & Pre/Post intervention & 1994 & N/A \\
\hline Mishara, 2012 & Canada & Police & Constabulary & $\begin{array}{c}9,367^{3} \\
14,286^{4}\end{array}$ & $\begin{array}{l}\text { Pre/Post intervention } \\
\& \\
\text { Intervention/Control }\end{array}$ & 1996 & 12 years \\
\hline
\end{tabular}

- Improved psychologica recruitment;

- Awareness training (se 5.5 and 7.5 hours deli personnel. Personnel receive an additional 16

- Centralized surveillan management system to during, and after deploy

- Crisis intervention team in the theatre environme

- Awareness training (u using an online format;

- Further awareness train plans, videos) available face delivery where pref

- Annualized mental heal health professionals;

- Peer support program.

- Awareness training (1 videos; 2 hours' duratiol

- Further awareness unclear duration) for ' $\mathrm{g}$ welfare personnel);

- Gatekeeper training for

- Welfare measures to between personnel;

- 24 hour crisis telephone

- Leadership training;

- Awareness training members of the Police

- Gatekeeper training ( members of the Police

- 24 hour crisis telephone 
- Gatekeeper training (le for chaplains, educatio social workers,

psychiatrists). Unclear

- Gatekeeper training (1

Table continued over ...

\begin{tabular}{|c|c|c|c|c|c|c|c|c|}
\hline Author, Year & Country & Population & Coverage & $\begin{array}{c}\text { Effective } \\
N^{1}\end{array}$ & Design & $\begin{array}{c}\text { Date of } \\
\text { Implementation }\end{array}$ & $\begin{array}{c}\text { Follow-up } \\
\text { Period }\end{array}$ & Intervention \\
\hline Warner, 2011 & USA & Military (Army) & Unit & 141,667 & Intervention/Control & 2007 & Not Stated & $\begin{array}{l}\text { - Awareness training (lec } \\
\text { Unclear who delivered t } \\
\text { - Further awareness trai } \\
\text { duration) for chaplain } \\
\text { mental health personne } \\
\text { training; } \\
\text { - Gatekeeper training (lec } \\
\text { for peer support personn } \\
\text { - Policy revisions to me } \\
\text { screening procedures for } \\
\text { - Centralized surveillance } \\
\text { - Behavioral health risk a } \\
\text { - Suicide postvention serv } \\
\text { - Reintegration and dec } \\
\text { days' duration). }\end{array}$ \\
\hline Welch, 1998 & South Africa & Police & ate & 10,000 & Pre/Post intervention & 1998 & 5 months & $\begin{array}{l}\text { - Awareness training (unc } \\
\text { members of human re } \\
\text { support services; } \\
\text { - Gatekeeper training (u } \\
\text { by members of human } \\
\text { support services; } \\
\text { - } 24 \text { hour crisis telephone } \\
\text { - Life skills and stress } \\
\text { (unclear duration) delive } \\
\text { resources and/or employ } \\
\text { - Crisis intervention team } \\
\text { - Suicide postvention serv } \\
\text { - Changes to media repo } \\
\text { the suicide of an officer; }\end{array}$ \\
\hline
\end{tabular}

${ }^{1}$ Numbers taken either from study reports or, where this information was not provided, from official statistics for the appropriate time period. Where this column is blank, numbers were unable to be calculated either from the study report or from official sources. 
${ }^{2}$ This figure differs to that reported in the study, and from a related review, as this figure represents the average size of the population over the study period, rather than the total number of personnel included in the dynamic cohort.

${ }^{3}$ Pre/Post-intervention analyses.

${ }^{4}$ Intervention/Control analyses.

${ }^{5}$ Although the program is ongoing and is still being rolled out to constabularies in both the USA and Canada. 


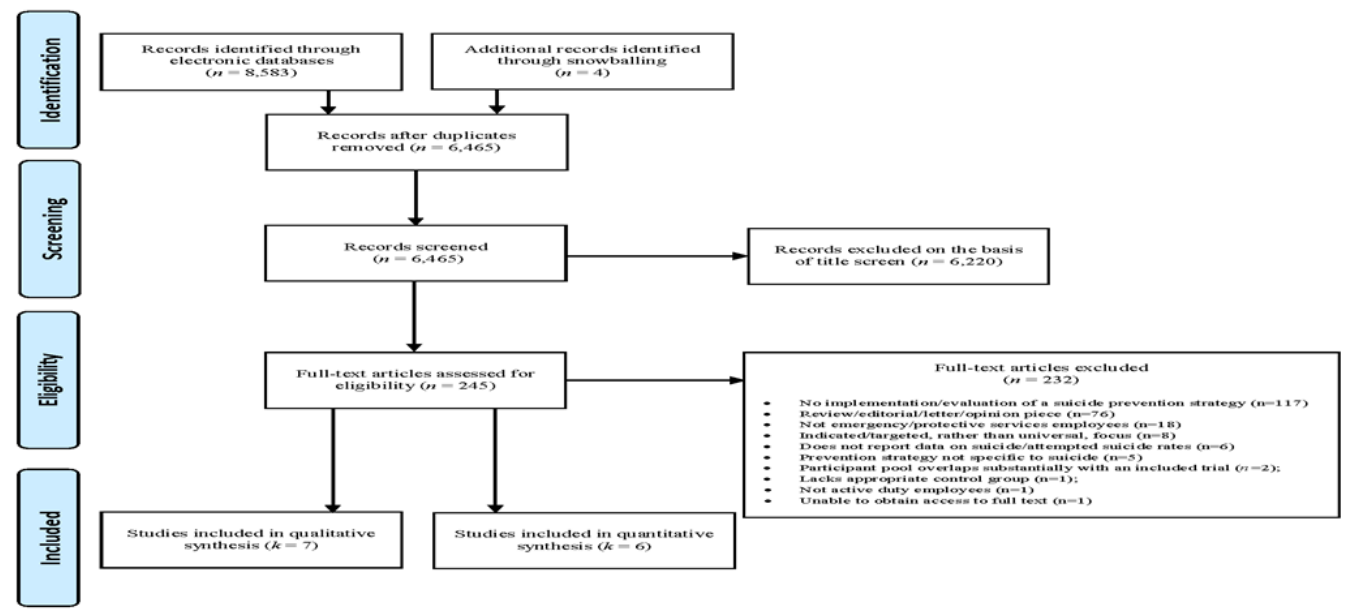

Notes: A A included in the review

Figure 1.

dentified following a systematic search of the literature for systems-based suicide prevention programs for

Figure 1 . 


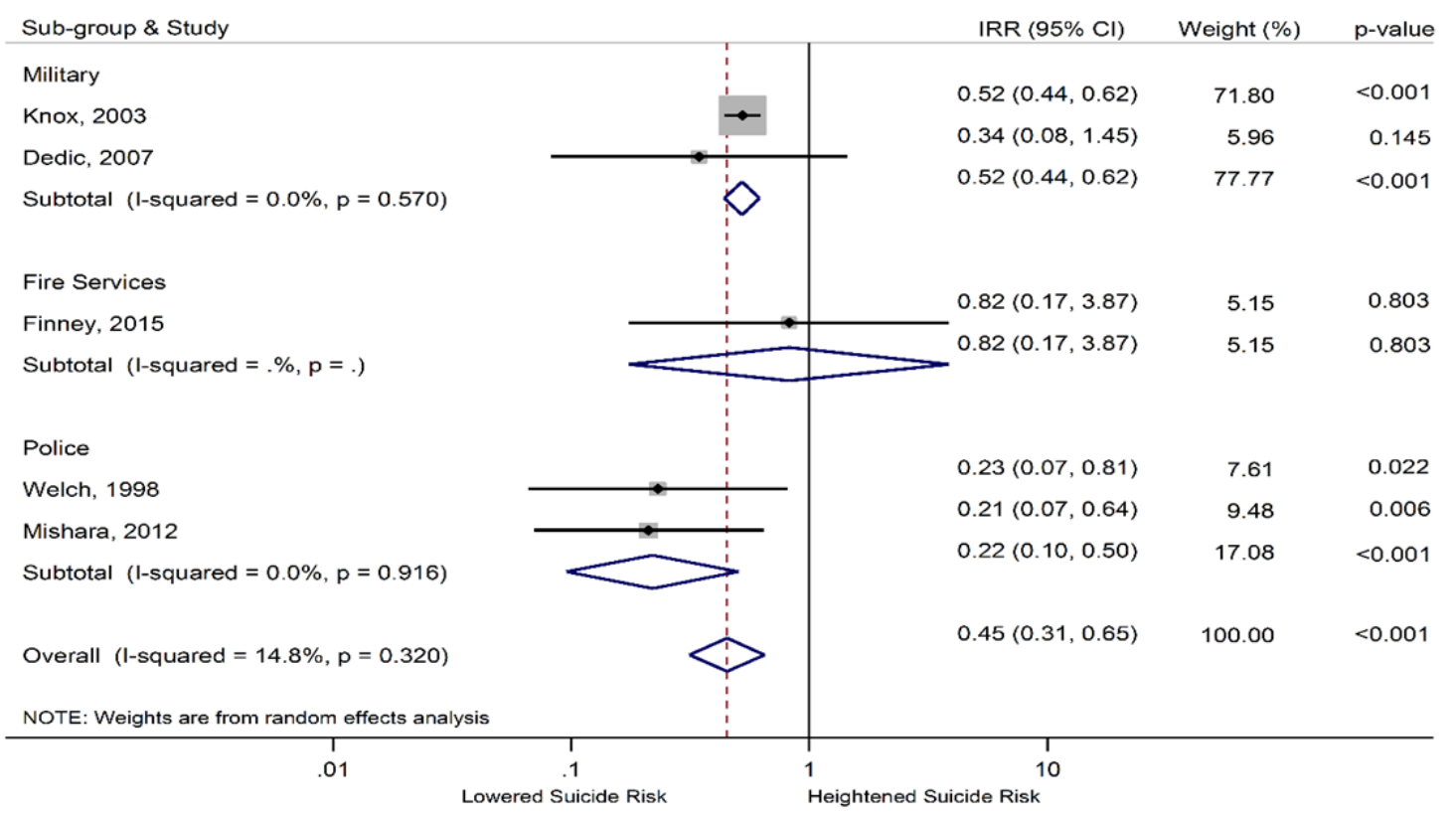

Figure 2 .

This article is protected by copyright. All rights reserved 


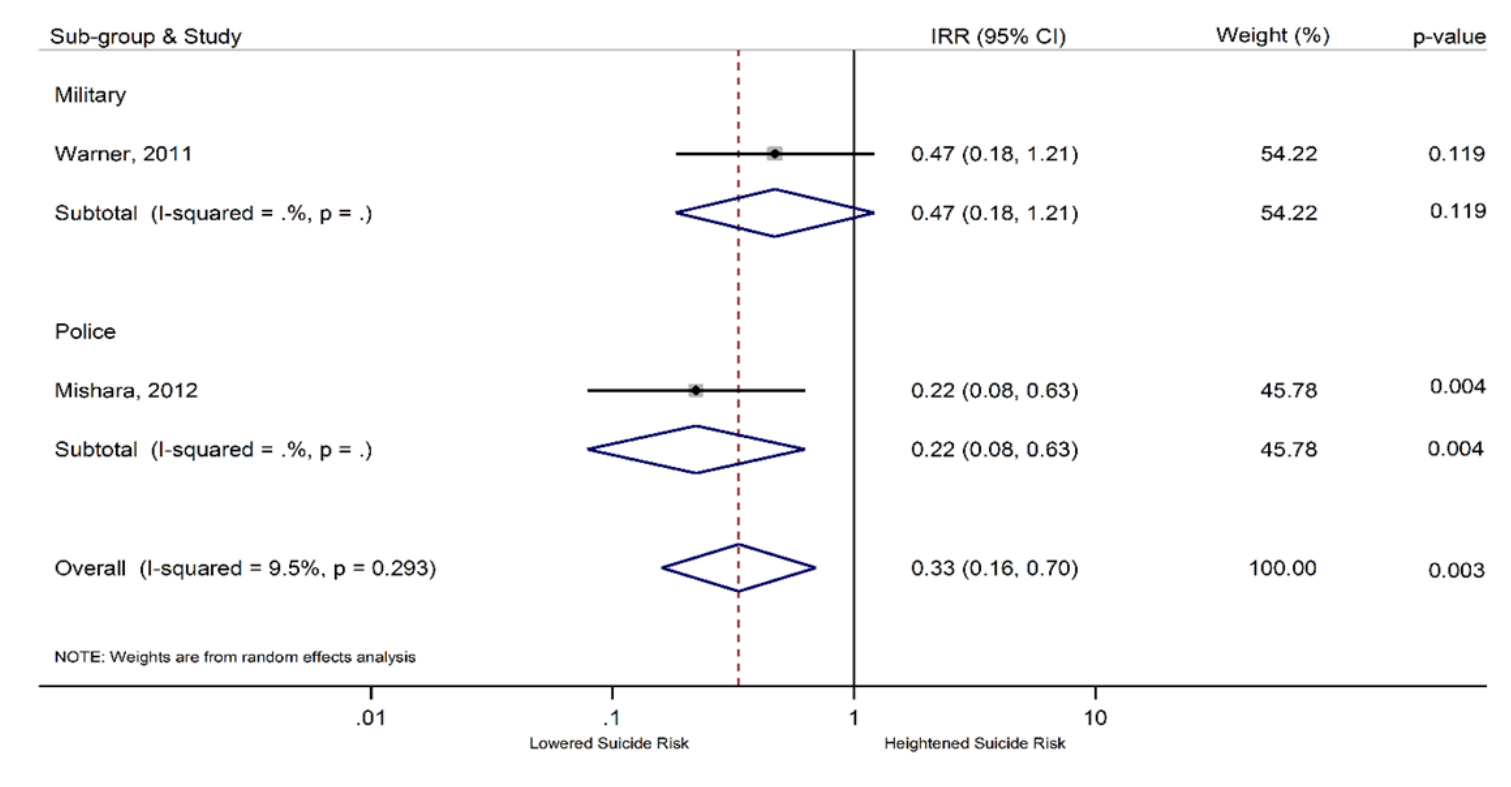

\section{Figure 3 .}




\section{University Library}

\section{- M M I N E R VA \\ A gateway to Melbourne's research publications}

Minerva Access is the Institutional Repository of The University of Melbourne

Author/s:

Witt, K;Milner, A;Allisey, A;Davenport, L;LaMontagne, AD

Title:

Effectiveness of suicide prevention programs for emergency and protective services employees: A systematic review and meta-analysis

Date:

2017-04-01

\section{Citation:}

Witt, K., Milner, A., Allisey, A., Davenport, L. \& LaMontagne, A. D. (2017). Effectiveness of suicide prevention programs for emergency and protective services employees: A systematic review and meta-analysis. AMERICAN JOURNAL OF INDUSTRIAL MEDICINE, 60 (4), pp.394-407. https://doi.org/10.1002/ajim.22676.

Persistent Link:

http://hdl.handle.net/11343/292606 